\title{
Triple Play and Interactive Digital Pay TV
}

\author{
Fanbin Zeng (Corresponding author) \\ $\mathrm{PhD}$ student, The School of Journalism and Communication, Renmin University of China \\ 59 Zhongguancun Avenue, Beijing 100872, China \\ \& Assistant Professor, College of Journalism and Communication, Jinan University, Guangzhou 510632, China \\ E-mail: zengfanbin@vip.sina.com \\ Tianyi $\mathrm{Wu}$ \\ College of Journalism and Communication, Jinan University, Guangzhou 510632, China \\ E-mail: neptuneiss0225@gmail.com
}

Received: September 4, 2012

Accepted: September 19, 2012

Online Published: October 31, 2012

doi:10.5430/jms.v3n4p15

URL: http://dx.doi.org/10.5430/jms.v3n4p15

This Project was financed by 2012 General Foundation of the Twelfth Five-Year Plan of Guangzhou Philosophy and Social Science Research (Grant Number: 2012YB31; Grant Title: Effect of Time Spent Online and Patterns of internet use on Real-life Political Participation: Based on Empirical Study on Internet Users in Guangzhou)

\begin{abstract}
According to maintenance staff of Chinese YiXiu network, in order to survive in the competition of triple play, to seize the commanding heights of business development, and to build the core competitiveness, the State Administration of Radio, Film and Television planned to invest 2.32 billion RMB to promote the high-definition interactive projects. The maintenance stuff stated that the program will adopt the mode, of which the installation fee of the high-definition interactive boxes will be supported by corporations, the proliferation will be carried out in a large scale, and the whole-business promotion will be adopted. While the high-definition interactive set-top box will be installed in the households of certain areas, the program will also promote digital TV, interactive TV, personal broadband business and pay-program etc. The program planned to apply the high-definition interactive function into 1.8 million households that already have digital TVs within 3 years. One handred thousand households will be installed with high-definition interactive function in 2011, 800 thousand in 2012, and 900 thousand in 2013. Therefore, in which way does triple play cooperate with interactive digital pay-TV and how can they promote the development of the premium channels? The followings are giving answers.
\end{abstract}

Keywords: Triple play, Interactive digital TV

\section{The Concept of Triple Play}

Triple play, known as "digital convergence" in Taiwan, refers to the concept that through the technological transformation of three networks, including telecommunications network, computer network and cable television network, to provide integrated multimedia communication services including voice, data, image etc. At the current stage, triple play means to merge radio transmission, communications transmission and computer transmission in the information transmission. It does not mean the telecommunications network, computer network and cable television network will be converged in a physical way, but refers to the integration of high-level business applications. Triple play applications are broad, covering many fields such as intelligent transportation, environmental protection, government work, public safety, safe house etc. In the future, we can watch TV and surf the Internet via phones, making phone calls and surf the Internet on television, and computers can be used to make phone calls as well as watch TV. The functions of the three will be overlapped.

Such integration of network, communications and broadcasting technology gathers a variety of media onto a single platform and thus will break the boarders of their former forms. Within the development of media industry, the main problem faced by triple play is the integration between the telecommunications network, which functions as the 
promotion of information transmission channel, and radio and television network, which possesses the advantages of propagating information. Triple play ends the times when radio and television network monopolized in information transmission while telecommunications monopolized in broadband operation. It also clarifies the reciprocal entry norm - when under appropriate conditions, the radio and television enterprises can operate value-added telecommunications services and businesses like Internet accessing which based on the cable network. The state-owned telecommunications enterprises that under the supervision of the relevant departments, can engage in the production of radio and television programs such as political affairs programs, signal transmission of Internet audio and video programs, and the services of broadcasting audio-visual current affairs programs, IPTV transmission service and mobile TV distribution services, etc.

\section{Overview of the Development of Foreign Triple Play}

\subsection{The Triple Play of the United States}

From 1970 to 1990, in order to protect new-born cable television industry from supplanting by monopolistic Telecom Company by means of unfair competitions, the Federal Communications Commission banned telecommunications companies to operate the cable business. In the early 1990s, the Federal Communication Commission considered that as the cable television industry had undergone great changes after the integration, telecommunications companies should be allowed to enter the market of video program in order to promote the diversification of video programming. Therefore, it proposed to the Congress to repeal the ban on mixed operation. However, the suggestion was not accepted. Since the end of 1992, several U.S. telecommunications companies had sued the Federal Communication Commission to the Federal Court, stating that FCC had violated the freedom of speech and they won the case eventually. These proceedings eventually led to the publication of the Telecommunications Act of 1996. Telecommunications Act of 1996 stipulates that the cable operators and its subsidiary bodies do not have to apply for the concessions before engaging in telecommunications services and the Concession Management Institution shall not prohibit or restrict cable operators and its subsidiary bodies to provide telecommunications services, nor impose any conditions on their services. Telecommunications companies can provide services through wireless communication, cable television system and the opened video system. This law completely broke the restrictions of mixed operation on the U.S. information industry and intensified the competition in the field of basic telecommunications. It allowed the mutual penetrations in the businesses of long-distance call, local call, radio, cable $\mathrm{TV}$, and video services. It also allowed various types of telecommunications operators to buy each other's stock. All the above contributed to create a legal environment of free competition. As a result, the entire telecommunications market has gained unprecedented competitive accessing permission. Companies with cable and optical fiber transmission signals took advantages of their advanced equipments to enter the telephone and network markets. And by upgrading their equipments and incorporating small companies, telephone companies began to expand their services in internet and television. The differences of service in different fields of companies were decreasing and the tendency of the integration of voice-video-data model had become increasingly common and was moving towards voice-video-data-wireless model.

The development of U.S. triple play has gone through four stages: protecting radio and television enterprises, no mutual access, gained the mutual access right through litigation and formally mutual open. The competition was intense in the late stage.

\subsection{The Triple Play of Britain}

The Britain published a new "Telecommunications Law" in 2003 and set up a new integrated regulation agency - Ofcom. This independent department integrated the original five regulation agencies (Telecom Authority, Independent Television Commission, Broadcast Standard Commission, Wireless Authority and Wireless Communications Bureau) and divided itself into 7 departments: Content Standards Department, Legal Affair Department, Ministry of Foreign Affairs and Management, Strategic Market Development, Spectrum Policy Department, Competitive Market Department and Operation Office, according to their horizontal functions. Ofcom's five major goals are the followings: supporting and protecting all consumers in the United Kingdom, ensuring the interests of the citizens, promoting competition and innovation, maintaining and consolidating the UK's communications infrastructure, and simplifying and reducing the regulations while maximizing the value. The UK regarded radio, television and telecommunications networks as a unified electronic communication network. The unified management greatly reduced the consultation costs between regulatory agencies, improved the work efficiency, especially expedited the settlement of the integration policy issues, broke the various barriers in the field of information and promoted the further development of the information technology and business in Britain. British Ofcom analyzed and compared ordinary households' usage of communications services and found out that under the 
same standard of service, in terms of the family share of costs, households in the United Kingdom is $4 \%$ lower than that in Italy, 17\% lower than that in France, 22\% lower than that in Germany, and 46\% lower than that in Spain. However, this kind of competition seems to have a certain impact on the application expansion of new technology.

The "Cable Broadcasting Act", published in 1992, allowed cable TV companies to concurrently operate telephone service, and then decided to gradually phase out the limitations of telecom operators' engaging in radio and television service, allowing them to provide Internet services to households with no access to cable TV. The "Communications Act", published in 2003, provided a general authorization system for telecom service operation, which indicated that licenses are not needed, still operating radio and television service required license. Besides, both radio and television enterprises and telecommunication companies can operate integrated business. Similar to the United States, the United Kingdom implements supervision into the contents on the Internet and radio and television programs in different extent. Comparatively, the content regulation for the internet is more lenient: operators can provide consumers with hierarchical filtering software but are prohibited to provide inappropriate contents for teenagers. The regulation is stricter on radio and television contents as they are concerned with the preservation of civil rights like expression and right to know. Meanwhile, as radio and television maintain a public service nature, they should have been strictly regulated. It should adjust the relationship between the expression of freedom and public interests and meanwhile ensure the maximum freedom of expression.

British triple play has gone through three stages: no access, asymmetric entry, symmetry entry. Its business model includes: cooperation between telecommunications and broadcasting, telecommunications and broadcasting industry operate integration business individually, and non-fixed-bundle of contents and channel.

\subsection{The Triple Play of Japan}

With the development of triple play, the division of Internet and communication network is no longer necessary. Japan is working to develop the next-generation network-NGN. Though Japan has achieved triple play, the telecommunications industry, broadcasting industry and Internet industry still owns their network respectively. To simplify NGN's goal, it endeavors to eliminate the boundaries between these networks, to updates the network based on Internet technology, and to achieve the integration of various services. NGN assimilates the advantages of telecommunications, radio and television network and the Internet. It possesses the reliability and stability of traditional telephone network, flexibility and economical of IP network, and is faster, safer than the current communication network. The triple play also promotes the integration of user terminal. The increasingly popular informative home appliances in Japan are the combination of traditional home appliances and informative communication technology.

The challenge faced by Japan's triple play is the reconstruction of its law. Sasaki, an Executive Advisor of Fujitsu Research Institute, said in an e-mail interview that as the communication industry and the broadcasting industry in Japan individually belongs to independent legal system, therefore, up to now, the broadcasting industry such as NHK and the communication industry has been regulated and developed respectively. The two industries each have their own inherent vested interests, and there are many differences in their values and culture. Therefore, in order to promote the integration of communication industry and broadcasting industry, it is inevitably to copy with the problem mentioned above. In addition, the new services coming up recently are beyond the scope in the fields of communications of Broadcasting Act and legal regulations. Japanese Senior researcher of the International Communication Institute of Economic Research Qiu Chunhui, said that the Japanese Ministry of Internal Affairs planned to submit the draft of "Information and Communication Law" to the Congress in 2010. This law would unify 9 laws (such as the Radio Law, the Broadcasting Act, and the Electrical Communications Business Law etc.) concerning the industry of communication and broadcasting, in order to eliminate the fragmentation and create a free competitive environment for radio and television enterprises.

The Japanese Ministry of Internal Affairs came out a national information strategy_-"U-Japan" in 2004. This plan aimed to promote the construction and integration of wired network, wireless network, digital broadcasting system and the transmission network and to build a ubiquitous network. In this "U-Japan", fixed and mobile, technology and service, information industry and the whole society are closely connected and mutually supported in order to realize high overlaps in the information production industry, information service industry and digital content industry. The Ministry of Internal Affairs is Japan's unified integration regulation sector, and according to its function, it is in charge of information and communication department, which includes Information and Communications Policy Bureau, Integrated Communication Foundation agency and the Policy planning of postal service agency. The main functions of Information and Communication Policy Bureau are to formulate the policy of the development of broadcasting and communication industry and to manage cable television and broadcasting business. The main 
functions of the Bureau of integrated communication infrastructure are to manage broadcasting and communication facilities and businesses and to deal with the management affairs concerning about telecommunications and radio industry.

\section{The Development of China's Triple Play}

China's Triple play can date back to the 1990s. In 1994, Electronic Ministry jointed with the Ministry of Railways, Ministry of Electronic Power and the Radio and Television Department and set up the China Unicom, which aimed at breaking the monopoly of China Telecom, and its focus was on the paging business. In March 1998, the merger of the Ministry of Posts and Telecommunications and the Ministry of Electronics Industry fostered the formal establishment of the Ministry of Information Industry. Meanwhile, the Radio and Television Department changed to the current Administration of Radio, Film and Television. In the notice "The Functions, Internal Structure and Stuff Management of State Administration of Radio Film and Television" published by the Office of the State Council in1998 (No. 92), there is an non-executed text, "the Ministry of Information Industry take charge of the functions such as overall planning and managing the industry, arranging and formulating the teleological standard and system of broadcasting and television transmission network that originally belongs to the function of broadcasting and television transmission network (including wireless and cable television network)." In March 1998, the Economic and Cultural Research Center of the telecommunications industry research group, lead by Dr. Wang Xiaoqiang, who was the former deputy director of the Commission of Sports Reconstruction and now is the Economic Advisers of GDE Group, put forward a research report "The Strategic Development of China's Telecommunications Industry", and embarked on a "triple play" or "triple convergence" debate. At that time, the Radio and Television Department is starting the trunk construction of cable network provincially and nationally.

However, considering the security issues of ideology, triple play was halted. In September 17, 1999, the Office of the State Council introduced a document (No. 82). It is written in the document, "The telecommunications sector shall not engage in broadcasting business and radio and television department shall not engage in communications business. Both of them must resolutely implement the decision." The document also pointed out that, "Radio, television and their transmission network, have become an important part of the national information technology."

Of course, the development of the technology is irresistible. "Triple play" was first clearly introduced in the national 10th Five-Year Plan passed in March 15, 2001. It stated, "We should promote the triple play of telecommunications, television, and Internet." The National 11th Five-Year Plan passed in 2005 pointed out that, "We should strengthen the construction of information infrastructures such as broadband communication network, digital television network and the next-generation Internet and promote the triple play." The Outline of the 11th Five-Year Plan, adopted in March 14, 2006, raised "triple play" again, "We should actively promote the "triple play'. By constructing and improving the broadband communication networks and accelerating the process of accessing broadband network to users, to steadily push forward the construction of new generation of mobile communication network. Build a digital TV network integrated cable, terrestrial and satellite transmission. Create the next-generation Internet and accelerate the development of commercial application. Formulate and improve the network standard and promote the interoperability and the sharing of resources."

In January 1, 2008, the State Council reposted the notice- "Several Policies for Encouraging The Development of Digital TV Industry" (SCS [2008] 1). It was published by 6 ministries, of which are the Development and Reform Commission, Ministry of Science and Technology, Ministry of Finance, Ministry of Information Industry, and the State Administration of Taxation. It put forward that, "Use digital cable TV as an entry to accelerate the promotion and popularization of digital television broadcasting, to strengthen the construction of Internet information infrastructures such as broadband communication network, digital television network and the next-generation internet, to promote "triple play", to form a fairly complete digital TV industry chain, and to realize a coordinated development in digital television technology researching, manufacturing, transporting, accessing, and user services related industries." In May 23, 2008, the restructuring plan of the carrier was officially announced. China Unicom's CDMA network and GSM network were split up, the former merged into China Telecom and formed the new telecommunications, while the latter absorbed China Netcom and set up the new China Unicom. Railcom was merged into China Mobile as its wholly owned subsidiary. Satcom's basic telecom business will be merged into China Telecom. In December 4, 2008, the Ministry of Science and SARFT jointly signed the "Independent Innovation Cooperation Agreement of National High Performance Broadband Information Network \& China's Next Generation Broadcast Networks" and proposed to build the next generation broadcasting television network (NGB) in 10 years. It will be made a new generation national information infrastructure that triple play will be its basic characteristic and will meet the developing requirements of modern digital media and information services industry. 
In January 2009, China Mobile, China Telecom and China Unicom had individually got the TD-SCDMA, CDMA2000 and WCDMA 3G licenses, which marked the three new operators had entered a new telecommunication era with full-service competition. In May 19, 2009, the State Council approved the notice of National Development and Reform Commission-“Advises for deepen economic reform of 2009" (SCS [2009] No.26). This document stated that we should implement the provisions of the State, achieve the two-way access for broadcasting and telecommunications companies, and make a substantive progress in 'triple play'(the Ministry of Industry and Information Technology, SARFT, the Development and Reform Commission, and the Ministry of Finance are responsible for that). In July 29, 2009, SARFT issued the notice-"Several Opinions on the Accelerating Development of the Radio and Television Wired Network", which pointed out that speeding up the development of radio and television cable network were significant for promoting the reform and development of China's radio, film and television industry. And it also promoted triple play as well as the construction of national information.

In January 13, 2010, the State Council executive conference clearly decided to accelerate the process of triple play, and clarified the timetable. In March 12, 2010, Industry and Information Technology Minister Li Yizhong accepted an exclusive interview of Xinhua News Agency. He revealed that the triple play pilot program is expected to be introduced in May and started in June. The core of triple play is to find the entry point of the two-way access so that the broadcasting industry can enter some business in telecommunications industry with permission and the state-owned telecommunications enterprises can enter radio and television business according to the regulations. In early April, the Ministry of Industry jointed Administration of Radio, Film and Television submitted the first draft of "triple play pilot program" to the Leading Group of the State Council. However, the draft was not approved but required to revise and be handed in again in the early May.

At the end of June 2010, triple play pilot city list (includes 12cities) together with the pilot program were officially announced. Triple play has finally entered a substantive stage. In July 1, 2010, the triple play pilot city list was finally formally introduced under the strong State's intervention. After all, the overall program had been gone through 15 modifications and 2 years' discussion, and the pilot program had been gone through 5 modifications and was almost at the risk of failing.

The first phase of pilot cities of triple play:

In June 30, 2010, the General Office of the State Council announced the first triple play pilot areas (cities) as the followings:

The provincial capital, the capital, and some cities (12): Beijing, Dalian City, Liaoning Province, Harbin City, Heilongjiang Province, Shanghai, Nanjing City, Jiangsu Province, Hangzhou City, Zhejiang Province, Xiamen City, Fujian Province, Qingdao City, Shandong Province, Wuhan City, Hubei Province, Zhutan area, Hunan Province, Shenzhen City, Guangdong Province, Mianyang City, Sichuan Province.

The Second phase of pilot cities of triple play:

In December 30, 2011, the General Office of the State Council released the second phase of pilot cities of triple play:

1) Municipalities (2): Tianjin, Chongqing.

2) Separately listed cities (1): Ningbo City, Zhejiang Province.

3) The provincial capital and capital city (22): Shijiazhuang City, Hebei Province, Taiyuan City, Shanxi Province, Hohhot City, Shenyang City, Liaoning Province, Changchun City, Jilin Province, Hefei City, Anhui Province, Fuzhou City, Fujian Province, Nanchang City, Jiangxi Province Jinan City, Shandong Province, Zhengzhou City, Henan Province, Guangzhou City, Guangdong Province, Nanning City, Haikou City, Hainan Province, Chengdu City, Sichuan Province, Guiyang City, Guizhou Province, Kunming City, Yunnan Province, Tibet Autonomous Region-Lhasa City, Xi'an City, Shanxi Province, Lanzhou City, Gansu Province, Xining City, Qinghai, Yinchuan City, Xinjiang Uygur Autonomous Region-Urumqi City.

4) Other cities (17): Yangzhou City, Jiangsu Province, Taizhou City, Nantong City, Zhenjiang City, Changzhou City, Wuxi City, Suzhou City, Xiaogan City, Hubei Province, Huanggang City, Ezhou City, Huangshi City, Xianning City, Xiantao City, Tianmen City, Qianjiang City, Foshan City, Guangdong Province, Yunfu City.

However, there are some problems in Chinese triple play. The first one is the conflict of interests between the broadcasting and telecommunications. At the beginning of the development of triple play, telecom operators were more active than radio and television operators because they felt that in the case of large-scale household broadband, they must provide users with more valuable contents and services. After announcing the pilot cities, telecom operators generally felt that more policies seem to tilt to the radio and television department. There were no objection 
to the content controlled by the radio and television department but telecommunications sector were not satisfied with the user billing management being controlled by the integrated broadcast control platform.

In the triple play, the radio and television is interested in Internet-accessing business. Though the policy allowed radio and television to operate Internet business, it limited that cable TV network is the only access, yet the international gateway to the SVA is closed. Therefore, if radio and television want to carry out in Internet business, they are not able to bypass the telecom operators. In this way, the interests between the broadcasting and telecommunications influenced the process.

In addition, the national cable companies cannot be established soon. As rationalizing the various relationships between the cable companies, the state investment, and private capital will take some time, it requires a lengthy process to form a national cable network company. Before the formation of the national companies, regional radio and television companies are difficult to compete with the national telecom operators. Radio and television networks are basically still in a four-run decentralized state.

Triple play can promote the common development of the cultural industry and the information industry, introduce the competition, stimulate cultural consumption and stimulate economic growth. Triple play brings lots of convergence opportunities to the broadcasting and telecommunications and will bring the following businesses:

\subsection{Radio and Television Content + Telecom Fixed-Line: IPTV}

SVA is the department in charge of the video and owns the video license. Telecommunications network are bidirectional network and have customer base and customer service advantages. In the case of the current telecom operators have not yet got integrated video license, radio and television broadcast license and telecom operators can cooperate to carry out IPTV services.

\subsection{Wireless Broadcasting Radio + the Telecom Mobile Communications: CMMB Mobile TV and Other Wireless} Multimedia

There is no bandwidth limit in broadcast transmission, but you cannot interact with the on-demand. The telecom mobile communication dissemination is limited by the bandwidth, but it is suitable for two-way interactive programs. Moreover, telecom operators have wireless access. Wireless provides multimedia with resource access.

\subsection{SVA Fixed-Line + Telecom Internet Export Bandwidth: Wired Broadband}

Having two-way cable network, it can carry the basis of broadband services, but is lacking of international outlet bandwidth. After telecom reorganization, fixed-line resource distribution of different operators is different, but all have international outlet bandwidth. When wired do not get the export bandwidth qualification, cable and telecom operators can cooperate on wired broadband services.

\subsection{The Radio and Television Content + Internet Channels: Internet Video}

At present, the channels of transmission of radio and television are wired network, ground, satellite and so on. Cable TV is the main channel. With the improvement of Internet penetration and China's rapid growth in the number of Internet users, radio and television content can take advantage of the Internet channel resources to carry out the business of Internet video.

\subsection{Radio and Television Cable Channels + Internet: Wired Internet}

With the completion of the two-way transformation of the wired network, cable network can carry out interactive business. With huge amounts of home users, huge sea of Internet content can be used by wired network. The cooperation of the cable network and Internet content providers can succeed.

Following contents are the influences triple play can cause on the development of interactive digital TV in China and then how to promote the chance to purchase the pay-TV.

\section{Interactive Digital TV of Triple Play in China}

Triple play policy introduced in 2010 is a milestone in interactive media industry. It marks the interactive media industry around the radio and television entered a period of rapid development. Interactive digital television is also known as interactive television or interactive digital television. It sets bidirectional wide network multimedia technology in one. The TV and high-definition interactive set-top boxes are its terminal. It provides users with HD channels to watch, high-definition video on demand, online games, pay television, distance education and other video and application services. Interactive digital television is the main service of radio and television cable network operators. 


\subsection{Concept and Functions of the Interactive Digital TV}

Interactive digital television is a playback in digital TV platform. It has two-way communication with the audience and play platform and is a new type of television transmission. This transmission mode allows the user through the remote control and the TV set-top boxes to control remotely to select a channel playback system to select TV programs. It also use telephone and cable networks as information loop to send personal wishes to broadcast platform. This way can achieve the purpose of selecting channels. It also can send the demands of the audience to the broadcast platform through telephone or SMS. Through these two ways, the audience can get the information they want or even influence or change the program contents being broadcasted by individual wishes.

Interactive Digital TV was first promoted in Europe. For example, as early as 1999, BskyB Company took advantage of the interactive features of the Internet and digital technology to pioneer interactive sports channel. When watching the game, the audience could freely choose the viewing angle, replay, close-up, or slow motion, information readily available to each team and race footages and even favoring a particular team through the TV set-top box and the remote control. The number of audience once daily grows amazingly by 10,000 when the company launched the interactive sports channel. Now, the interactive channels have covered shopping, electronic program guide, businesses online interactive TV advertising and so on. In 2001, BBC first used the interactive services in Wimbledon tennis tournament, while providing five venues for users to choose including navigation page and score.

Interactive digital TV has the following three functions:

1) TV Re-watches.

One feature of the interactive home TV is the television re-watches. You can re-watch television programs.

2) TV on Demand

Another feature of interactive family TV is TV-on-demand. The program covers the popular channels of movies, TV shows, sports, education finance and economics. It updates monthly and you can see or stop it at any time.

\section{3) The Program Recording}

The last one feature of TV interactive is program recording. You do not need to worry about missing a wonderful live. You are not limited in the prescribed time to watch the desired TV as before.

\subsection{The Development of Chinese Interactive Digital TV}

The development of interactive digital TV in China began in 2001. By the end of 2010, China's two-way radio and television networks has covered a user base of nearly 50 million after having been developed for nearly 10 years. According to the statistics analysis of streaming media network, the actual interactive digital TV users are less than $10 \%$, only 4.17 million households. At present, the main users centered in the East China-Shanghai, Jiangsu, Zhejiang and other East China coastal areas. The main factors that restrict the development of interactive media services goals of triple play include policy, network infrastructure, platform, operating mode etc. With the carrying out of national triple play pilot project, these constraints are gradually eliminated, and interactive media services concentrating on the radio and television content are gradually embarking on the track of sustainable development.

Interactive media services centering on achieving the goal of triple play mainly means that the carrier-qualified Broadcasting and Telecommunications operators provide users with radio and television content, value-added services, related business platforms, terminals and other key services by means of the Internet, broadband networks, mobile communications networks and radio and television networks. Such kind of service can date back to the late 1990s when internet streaming media video was popular. Though at that time it was at the beginning stage of development, it has already had the basic characteristics of interactive media services, including IPTV, interactive digital TV and so on. With the emergence of all kinds of interactive media services and applications, manufactories of radio and television, broadcasting, telecommunications and Internet are involving in this emerging industry. Meanwhile, they developed a large number of users in a relatively short period and the industry scale is also rising, which shows the vitality and tremendous development potential of interactive media services. The Government departments also carried out appropriate policies and regulations to encourage and regulate the development of the industry. Also, the industry chain of interactive media services has gradually formed and the new business model is being made clear. In 2010, the introduction of triple play policy is a milestone to interactive media industry, which marks that the interactive media industry has entered a period of rapid development.

From the policy perspective, the promulgation and implementation of national Triple Play policy in 2010 formulate the rules and the roles of the game initially and laid the foundation for the refinement and implementation in the future. As technology research centering on interactive media platform has made initial progress, the operators are 
made possible to provide users with a variety of high quality, interactive and value-added broadcast and TV services. At present, however, the interactive media services platform have disadvantages such as low content compatibility, poor differentiating service ability and interactive expansion ability etc. With the expanding range of interactive media services, such limitations will be gradually exposed. In terms of business model, with the gradual formation of industry pattern, the cooperation mode of the roles on the industrial chain is increasingly clear and solid. However, a new business mode has not yet been completely mature.

The expansion of Interactive media services aiming at triple play needs the support of the service platform, which is the engine and base for various services. By deploying the complete and professional interactive media platform, business operators can carry out a variety of triple play interactive media businesses and manage all the links in the business value chain. On that basis, the achievements can be further expanded to other areas, and form a complete interactive media services system. The Interactive media business platform aiming at triple play is now established on the basis of the requirements of the spread of radio and television content, and centered on the technologies like audio and video streaming media. Its main business entities are radio and television operators and telecommunications operators. The specific construction work of the platform was undertaken by various professional platform software companies, such as ZTE, Huawei, Onewave, UT Starcom etc. Project construction and implement ability of these companies will have a direct impact on the actual usage. Therefore, the system platform software companies play an extremely significant role in the construction of interactive media operation platform.

With the rapid development of triple play interactive media business, the booming number of users, the changing needs of users, and the increasing add-value business provided by operators, are generating huge demands on the system platform software. According to the research, the market demand of the interactive media business platform software in 2010 was 2.187 billion RMB, and the market will continue growing in a rapid speed. By 2014, the market is expected to reach 8.612 billion RMB, maintaining compound annual growth rate of $40.8 \%$. With the continuous advancing of related work, the interactive media business platform will expand its own capacity catering to the larger market. Not only will it promulgate the radio and television contents, but needed to further satisfy the developing requirements of social management, culture and entertainment, new type advertising, IT research and development, industrial and agricultural production, modern education and other industries. The interactive media business platform is expected to make a breakthrough in the following area: the ability to support broadcasting, exchanging, storing, searching and other services simultaneously. Such ability is required to be provided on the terminals simultaneously or as a combination according to the needs of customers.

\subsection{Adding User Experience in Interactive Digital TV and Increasing Their Willing to Pay}

Adding user experience in interactive digital TV and increasing their willing to pay. Interactive digital TV makes the media communication transferred to two-way interaction. When there were boundaries of communication channel, the broadcasting and television media was in one-way transmission and the audience was in passive receptive position. With the emergence of internet as a new media, audience was able to play in the role of disseminator. After the completion of triple play, more options are given to the audience as a medium user and an active media disseminator. For example, the interactive TV operations in Guangzhou has "horizon interactive TV" (company's name is Guangzhou Visual Picture Digital TV Technology Development co., LTD), which is a new digital life interactive TV platform created by Guangdong cable TV and Shenzhen Horizon holding enterprises. It has two-way interactive function. On one hand, interactive TV user could select all the video contents and different types of interactive services through terminal set-top boxes. On the other hand, interactive TV subscribers can communicate with interactive TV by sending requirements to the back office service center via a remoter. It has the following functions:

\section{1) Video Services}

In the era of analog TV, the audiences are passive recipients that are only passively subjected to the programming timetable and the arrangement of the program content. The introduction of Horizon Interactive TV allows the viewers to become the real master of TV and can meet their personalized demanding.

A. Subscribing TV programs: user can choose the TV programs according to their own preferences. The system will transfer the programs to user's set-top box for the audience's convenience.

B. Replaying the programs: users can download and replay the broadcasted television programs any time they want.

C. VOD on demand: offering movies, TV serious, feature programs, online music on demand.

2) Voice services 
Horizon has voice function, which enables the consumers to effectively communicate with other users and service provider.

A. Calls between users are free.

B. The communication between users and service providers is more effective: users obtain the information from the television by the remoter and can talk to service providers both conveniently and effectively.

C. The customer cost of the service company is lower. User can enjoy greater efficiency and convenience compared to traditional CALLCENTER.

3) Life assistant services

A. Information search. The system is equipped with a powerful auto-search function: when typed into user's demand via the remote control, the system is able to complete the searching and play the program automatically such as presenting the latest electronic program guide, weather report, and traffic forecasts etc.

B. Classified information: the system will set up the classified information or specialized channels, like cars, real estate, food, financial, investment, education and training, travel, airfare hotels, beauty, family physicians, child care, recreation and sports fitness, appliances IT, recruitment, shopping, entertainment, games, clubs, KTV, etc. Users could watch or subscribe the classified information according to their needs. Online reservation or purchasing the relative products or services is also provided.

C. Utilities, traffic revenue, phone bill payment etc.

In fact such kind of TV has part of the functions of websites:

1) The advertising promotion: They can decide to accept certain ADs according to the needs of the audience.

2) The online sales of goods: interactive TV users could simply use the remoter to look up, subscribe and purchase goods at home, fulfilling the ultimate goal of the advertisers.

At present, the pay TV has been developed for eight years. Most of it is one-way transmission and users are passive receivers. The insufficient interaction has become one of the major obstacles that restrict the development of the industry. If users pay to watch an episode, which regularly broadcasted at 0:00, they have to wait until then. Such problem has been solved on the internet. As a result, the audience will definitely choose the internet when they pay to meet their entertainment needs. That's why that the combination of pay TV and interactive TV would be an imperative tendency. It is sure that, the interactive digital TV under triple play will content resourceful information (massive digital contents). Disseminating, transferring and exchanging between certain groups of people have better openness. It possesses the advantage of the full linkage with the production, transmission and feedbacks of information and the compatibility with IT systems. Simply put, the interactive media is a form of service that certain groups of people (the groups can be modified in dynamic ways) use, to obtain information like text, image, audio and video by virtue of computers, mobile phones, set-top box/TV, cars, production management terminals and other visual terminals. And it is the service that enables users to not only interact with the background content management and servicer provider platform, but also set the sequence of information obtaining and the effect of contents as well.

\section{References}

Do not let the digital convergence fail again. Commercial Times (July 13, 2010).

Glossary in Governmental report of Prime Minister. Renmin Web (July 17, 2010).

Li, Da. (2010). Digital television industry analysis report. [Online] Available: http://www.jic.cn/news/research/637.html

Seizing the Commanding Heights of Triple Play, Radio and Television Network Spent 2.3 Billion Expanding High-Definition Interactive TV. Shanghai Securities News (November 23, 2011).

Wang, Ru. (2009). British Ofcom's severe supervision and openness. Communication world weekly.

Yang, Kun \& Zhang, Yanxiang. (2011). First trial of interactive media service and platform of triple play. China digital TV. 